\title{
Meta-Analysis of the Effects of Human Disturbance on Seed Dispersal by Animals
}

\author{
JULIA S. MARKL, ${ }^{*}+\dagger+$ MATTHIAS SCHLEUNING,${ }^{*}+\dagger^{* * *}$ PIERRE MICHEL FORGET, $\dagger$ \\ PEDRO JORDANO, $\ddagger$ JOANNA E. LAMBERT,』 ANNA TRAVESET, ${ }^{* *}$ S. JOSEPH WRIGHT, † \\ AND KATRIN BÖHNING-GAESE*
}

${ }^{*}$ Biodiversity and Climate Research Centre (BiK-F) and Senckenberg Gesellschaft für Naturforschung, Senckenberganlage 25, 60325 Frankfurt (Main), Germany

†Muséum National d'Histoire Naturelle, UMR 7179 CNRS-MNHN, 1 av. du Petit Château, F-91800 Brunoy, France

†Integrative Ecology Group, Estación Biológica de Doñana (CSIC-EBD), Avda. Americo Vespucio s/n, Isla de La Cartuja, E-41092

Sevilla, Spain

§Department of Ecological Anthropology, One UTSA Circle, The University of Texas at San Antonio, San Antonio, TX 78249, U.S.A.

${ }_{* *}$ Institut Mediterrani d'Estudis Avançats (CSIC-UIB), C/ Miquel Marqués 21, 07190 Esporles, Mallorca, Balearic Islands, Spain HSmithsonian Tropical Research Institute, Apartado 0843-03092, Balboa, Republic of Panama

抽partment of Biological Sciences, Johann Wolfgang Goethe-Universität Frankfurt, Max-von-Laue-Straße 9, 60438 Frankfurt (Main), Germany

\begin{abstract}
Animal-mediated seed dispersal is important for sustaining biological diversity in forest ecosystems, particularly in the tropics. Forest fragmentation, hunting, and selective logging modify forests in myriad ways and their effects on animal-mediated seed dispersal have been examined in many case studies. However, the overall effects of different types of human disturbance on animal-mediated seed dispersal are still unknown. We identified 35 articles that provided 83 comparisons of animal-mediated seed dispersal between disturbed and undisturbed forests; all comparisons except one were conducted in tropical or subtropical ecosystems. We assessed the effects of forest fragmentation, hunting, and selective logging on seed dispersal of fleshy-fruited tree species. We carried out a meta-analysis to test whether forest fragmentation, hunting, and selective logging affected 3 components of animal-mediated seed dispersal: frugivore visitation rate, number of seeds removed, and distance of seed dispersal. Forest fragmentation, hunting, and selective logging did not affect visitation rate and were marginally associated with a reduction in seed-dispersal distance. Hunting and selective logging, but not fragmentation, were associated with a large reduction in the number of seeds removed. Fewverseeds of large-seeded than of small-seeded tree species were removed in hunted or selectively logged forests. A plausible explanation for the consistently negative effects of hunting and selective logging on large-seeded plant species is that large frugivores, as the predominant seed dispersers for large-seeded plant species, are the first animals to be extirpated from bunted or logged forests. The reduction in forest area after fragmentation appeared to have weaker effects on frugivore communities and animal-mediated seed dispersal than bunting and selective logging. The differential effects of bunting and selective logging on largeand small-seeded tree species underpinned case studies that showed disrupted plant-frugivore interactions could trigger a homogenization of seed traits in tree communities in hunted or logged tropical forests.
\end{abstract}

Keywords: frugivory, habitat fragmentation, hunting, meta-analysis, seed removal, seed size, selective logging, tropical forest

Meta Análisis de los Efectos de la Perturbación Humana sobre la Dispersión de Semillas por Animales

\footnotetext{
***Address correspondence to M. Schleuning, email matthias.schleuning@senckenberg.de H†These authors contributed equally to the article.

Paper submitted December 14, 2011; revised manuscript accepted May 24, 2012.
} 

Resumen: La dispersión de semillas por animales es importante para sustentar la diversidad biológica en ecosistemas forestales, particularmente en los trópicos. La fragmentación de bosques, la cacería y la tala selectiva modifican los bosques de muchas maneras y sus efectos sobre la dispersión de semillas por animales han sido examinados en muchos estudios de caso. Sin embargo, todavía se desconocen los efectos generales de los diferentes tipos de perturbación bumana sobre la dispersión de semillas por animales. Identificamos 35 articulos que proporcionaron 83 comparaciones de dispersión de semillas por animales entre bosques perturbados y no perturbados; todas las comparaciones excepto una fueron en bosques tropicales o subtropicales. Evaluamos los efectos de la fragmentación del bosque, la cacería y la tala selectiva sobre la dispersión de especies de árboles con frutos carnosos. Efectuamos un meta análisis para probar si la fragmentación del bosque, la cacería y la tala selectiva afectaban a tres componentes de la dispersión de semillas por animales: tasa de visitación de frugivoros, números de semillas removidas y distancia de dispersión de semillas. La fragmentación del bosque, la cacería y la tala selectiva no afectaron la tasa de visitación y estuvieron marginalmente asociadas con la disminución de la distancia de dispersión. La cacería y la tala selectiva, pero no la fragmentación, se asociaron con una reducción importante en el número de semillas removidas. Menos semillas de especies de árboles con semillas grandes que de semillas pequeñas fueron removidas en bosques con cacería o tala selectiva. Una explicación plausible de los efectos consistentemente negativos de la cacería y la tala selectiva sobre las especies con semillas grandes es que los frugivoros grandes, como los dispersores predominantes de especies de plantas con semillas grandes, son los primeros animales extirpados de bosques con caceria o tala. La reducción de la superficie de bosque después de la fragmentación pareció tener efectos más débiles sobre las comunidades de frugivoros y la dispersión de semillas por animales que la cacería y la tala selectiva. Los efectos diferenciales de la cacería y la tala selectiva sobre especies de árboles con semillas grandes y pequeñas sustentaron estudios de caso que mostraron que la alteración de interacciones planta-frugivoro podría detonar la homogenización de atributos de las semillas en comunidades de árboles en bosques tropicales con cacería o tala.

Palabras Clave: bosque tropical, cacería, fragmentación del hábitat, frugivoría, meta análisis, remoción de semillas, tala selectiva, tamaño de semilla

\section{Introduction}

Many plant species depend on animals for seed dispersal. On average, $90 \%$ of woody plant species in tropical forests produce fruits that are dispersed by animals, in particular by birds and mammals (Howe \& Smallwood 1982; Gentry 1988). Three principal hypotheses have been advanced to explain why seed dispersal in general, and animal-mediated seed dispersal in particular, is a crucial process in a plant's life cycle (Howe \& Smallwood 1982). In the escape hypothesis it is assumed speciesspecific pathogens, fungi, and herbivores occur in high densities near parent trees, which increases seed and seedling mortality close to the parent tree (Howe \& Smallwood 1982). The colonization hypothesis proposes that seed dispersal increases the probability that seeds reach new sites where they can germinate and establish (Howe \& Smallwood 1982). The directed-dispersal hypothesis suggests seed dispersal agents deposit seeds at sites that are particularly suitable for germination and recruitment (Howe \& Smallwood 1982). All 3 hypotheses posit that animal-mediated seed dispersal enhances seedling recruitment and is thus important for maintaining genetic diversity and plant population viability Jordano et al. 2011). Human disturbance can affect animal-mediated seed dispersal and natural regeneration of plant populations by altering any of these components of dispersal (i.e., escape, colonization, or recruitment).
Forest loss, fragmentation of forest remnants (Cordeiro \& Howe 2003), hunting (Peres 2000), and selective logging (Kirika et al. 2008) severely affect species and ecological processes in tropical forests (Morris 2010). Given that small forest fragments cannot support as many individuals as large, continuous forests, fragmentation often leads to the local extirpation of frugivores (Valdivia \& Simonetti 2007). Hunting reduces frugivore abundance directly and can result in the local extirpation of game species preferred by hunters, which often include large frugivores (Peres 2000; Peres \& Palacios 2007). Increased intensities of selective logging can also reduce the abundance of frugivores through decreased fruit availability and loss of forest structure (Lambert 2011). The effects of different types of direct human disturbance, such as hunting and selective logging, are usually impossible to separate because many intensively logged forests simultaneously experience high levels of hunting (Kirika et al. 2008; Babweteera \& Brown 2009).

If animal seed dispersers decrease in abundance or are extirpated, fewer frugivores might visit fruiting trees, fewer seeds might be dispersed (Kirika et al. 2008; Holbrook \& Loiselle 2009), and dispersal distances of seeds might decrease (Wright et al. 2000). These reductions in seed dispersal by animals can lead to increased postdispersal predation on seeds (Galetti et al. 2006), lower seedling recruitment (Cordeiro \& Howe 2003), and local plant extirpation and declining plant diversity (Terborgh et al. 2008). However, results of some studies 
show consistently negative effects of forest fragmentation and selective logging on animal-mediated seed dispersal (Graham et al. 2002; Guariguata et al. 2002), whereas others show positive effects of fragmentation and logging on seed dispersal (Farwig et al. 2006; Neuschulz et al. 2011). Such discrepancies may arise because researchers assessed different components of seed dispersal (e.g., visitation rates of frugivores, number of seeds removed by frugivores, and actual seed-dispersal distances [Schupp et al. 2010]) or focused on different types of plant species (e.g., small vs. large-seeded species [Menke et al. 2012]). Because seeds of many plant species must be swallowed to be dispersed, larger fruits and seeds generally require larger animals as dispersers (Lambert 1999; Moran et al. 2004). Therefore, hunting of large frugivores might affect large-seeded plant species more negatively than smallseeded plant species (Vanthomme et al. 2010).

There have been many studies of the effects of forest fragmentation and of direct effects of human disturbance, such as hunting and selective logging, on animalmediated seed dispersal, but to our knowledge there is no consensus on the overall effects of different types of human disturbance on animal-mediated seed dispersal. To address this gap, we conducted a meta-analysis to test whether forest fragmentation as well as hunting and selective logging affect animal-mediated seed dispersal. Fragmented forests occurred in landscapes that once supported continuous forest cover. Directly disturbed forests were modified by at least one human activity, such as hunting or selective logging. We investigated effects of forest fragmentation and hunting or selective logging on 3 components of seed dispersal: visitation rate of frugivores, number of seeds removed by frugivores, and mean seed-dispersal distance.

We examined whether forest fragmentation and hunting or selective logging differently affected visitation rate, seed removal, and seed-dispersal distance. We hypothesized that frugivore visitation rates are affected less by human disturbance of any type than are seed removal and dispersal distance because generalist frugivores can compensate for decreased visitation rates by specialized frugivores at disturbed sites (Menke et al. 2012) but are likely to remove fewer seeds and disperse them over shorter distances (Holbrook \& Loiselle 2009).

We asked whether effects on animal-mediated seed dispersal differed between forest fragmentation and hunting or selective logging. We hypothesized that hunting and selective logging have stronger negative effects on seed dispersal than fragmentation because direct human disturbance, particularly hunting, reduces frugivore abundance (Corlett 2007; Peres \& Palacios 2007), whereas forest fragmentation does not necessarily reduce the abundance of generalist frugivore species (Farwig et al. 2006).

We evaluated whether large-seeded species differ in their responses to fragmentation, hunting, and selective logging from small-seeded species. We hypothesized that large-seeded species are more affected by fragmentation and hunting than are small-seeded species (Moran et al. 2004; Vanthomme et al. 2010) because large animals are more likely to be extirpated, particularly in response to hunting, and large seeds require large animals as seed dispersers (Moran et al. 2004; Stoner et al. 2007b).

\section{Methods}

\section{Literature Survey}

We searched the literature with Web of Science. Our searches included all records through August 2010. We used a combination of "disturb* OR fragment* OR de-

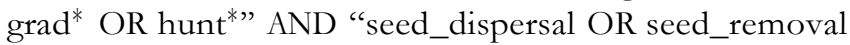
OR frugivor*." These key words matched 1642 articles. The abstracts of 151 of these articles indicated the research centered on effects of different types of human disturbance on seed dispersal interactions in terms of visitation rate, number of seeds removed, or seed-dispersal distance. We retained articles that compared at least one component of seed dispersal between at least one disturbed and one undisturbed site. We defined human disturbance as forest fragmentation, hunting, or selective logging. We only considered forest fragmentation studies in which fragments were $<120$ ha and continuous forest was $>600$ ha. We evaluated effects of fragmentation relative to forest size, not relative to degree of isolation or edge effects. We also considered studies in which forests were affected by hunting, selective logging, or both. Effects of hunting and selective logging were impossible to separate because most intensively logged forests also had high hunting pressure. Studies in which the effects of hunting or selective logging were obviously confounded with those of forest fragmentation were excluded.

We used the following conventions to gather data from case studies. First, if the same plant species was investigated in multiple studies, we considered each study independently (Morales \& Traveset 2009). Second, if a single study reported data on more than one plant species, then we considered each species independently (Aguilar et al. 2006). Third, if a single study reported results for $>1$ year, we randomly selected one of the years (Morales \& Traveset 2009). Fourth, if a single study evaluated fragments of different size, we compared the smallest fragment with the continuous forest (Myers \& Harms 2009). Finally, if a study was conducted at sites with different disturbance intensities, we compared the most disturbed site with the least disturbed site (Myers \& Harms 2009).

Following these conventions, we extracted mean values, standard deviations, and sample size for each component of seed dispersal in each disturbed and undisturbed forest. If possible, we collected this information from 
the source text. When we could not get this information from the source, we extracted it from the figures with graphical software (Tummers 2006). When information was incomplete, we contacted authors directly.

\section{Seed-Dispersal Components and Plant Traits}

We defined visitation rate as the number of visits of frugivorous individuals to a fruiting tree per unit time. We estimated seed removal in 1 of 2 ways: the absolute number of fruits or seeds removed from a fruiting tree by frugivores per unit time or the proportion of available fruits or seeds on a fruiting tree removed by frugivores. In 4 studies, fruits were removed from experimental fruit stations, and in the remaining 25 studies they were removed directly from a fruiting tree. We defined seed-dispersal distance as the mean dispersal distance of seeds from a focal tree; studies of seed-dispersal distance reported dispersal distances up to a maximum distance from the parent tree (range $20-50 \mathrm{~m}$ ). If mean dispersal distance and its standard deviation were not indicated by the authors, we calculated them from the provided distances that each seed was dispersed. To determine sample size, we recorded the number of focal trees or fruit stations or the number of seeds followed.

For each tree species, we also collected data on fruit and seed size from the original paper or, if necessary, from other sources. Fruit and seed size equaled the length of the longest axis of a fruit or seed, respectively. Fruit and seed size were closely correlated $(\log -\log$ scale: $n=51$ species, $r=0.79, p<0.001)$; therefore, we focused on seed size. We classified seeds as small $(<1 \mathrm{~cm})$ or large $(\geq 1 \mathrm{~cm})$ because small-gaped frugivorous bird species can disperse seeds up to a diameter of $1 \mathrm{~cm}$ (Moran et al. 2004). We extracted genus and family information for each tree species from the original sources and obtained geographic locations for each study site from the original paper or from Google Earth software.

\section{Formal Meta-Analyses}

For each comparison, we calculated the unbiased standardized mean difference (Hedge's $d$ ) between the mean values in undisturbed and disturbed forest with the following equation:

$$
d=\frac{X^{E}-X^{C}}{S^{E C}} J,
$$

where $X^{E}$ is the mean value of the response variable in disturbed (i.e., fragmented, hunted, logged) forest (experimental group), $X^{C}$ is the mean value of the response variable in undisturbed forest (control group), $S^{E C}$ is the pooled standard deviation of both groups, and $J$ is a term that corrects for bias due to small sample size (Gurevitch \& Hedges 2001). Negative effect sizes indicate animalmediated seed dispersal is lower in the disturbed than in the undisturbed forest.
We calculated effect sizes and conducted formal metaanalyses in $\mathrm{R}$ ( $\mathrm{R}$ Development Core Team 2010) with the metafor package (Viechtbauer 2010). Because we assumed effect sizes varied randomly among comparisons (Gurevitch \& Hedges 2001), we used random-effects models. We used 2 alternative statistical approaches (restricted maximum-likelihood [REML] and DerSimonianLaird [DSL]) that provided consistent results. To avoid redundancy, we present results from REML analysis throughout.

To test whether mean effect sizes from a set of comparisons differed significantly from zero, we assumed a normal distribution of effect sizes and their confidence intervals (z statistics [Viechtbauer 2010]). To test whether predictor variables influenced effect sizes, we used 3 different approaches. First, for multinomial predictor variables, we compared the null model, which only included the intercept, with a full model that included the predictor variable that assigned each comparison to a particular predictor level (Viechtbauer 2010). We compared the fit of the 2 models by conducting a likelihood-ratio test (LRT). For model comparisons, we fitted models with the DSL method because model comparisons are not meaningful for models fitted by REML. Model comparisons were used to compare effect sizes among different dispersal components (i.e., visitation rate, number of seeds removed, seed-dispersal distance) and among different continents (i.e., America, Africa, and Asia). We excluded Europe because only a single European study was available. Second, to test for effects of binomial predictor variables, we examined the heterogeneity of effect sizes with a $X^{2}$-distributed $Q$ statistic (Viechtbauer 2010). This approach compares variation between the groups of the respective predictor variable $\left(Q_{b}\right)$ with the residual variation within groups $\left(Q_{r}\right)$; the comparison of betweenand within-group variation is analogous to an analysis of variance approach. We used this approach to test effects of fragmentation versus hunting and logging and of large-seeded versus small-seeded species. Third, to test for effects of continuous predictor variables, we tested whether the estimated model coefficient for the respective predictor variable was significantly different from zero (assuming normally distributed confidence intervals [Viechtbauer 2010]). This approach was used to test for effects of the sizes of forest fragments (maximum size in case of various fragments) and of continuous forests on the different dispersal components. The sizes of forest fragments and continuous forests were $\log _{10}$ transformed.

\section{Autocorrelation and Publication Bias}

To account for potential bias due to spatial autocorrelation, we calculated Moran's $I$ values from the residuals of all meta-analysis models on the basis of a spatial weights matrix derived from the spatial neighborhood of each 
comparison (Bivand et al. 2010). We defined the neighborhood of each comparison by the 4 nearest locations. We evaluated the statistical significance of Moran's $I$ values against 999 permutations of the spatial arrangement of sites.

We tested for phylogenetic autocorrelation with the ape package (Paradis et al. 2004). We calculated a distance matrix on the basis of taxonomic relations of the tree species and tested whether the residuals were affected by the taxonomic similarity at a given taxonomic level (i.e., family and genus in our analyses).

Because significant results are more likely to be published than nonsignificant results (Gurevitch \& Hedges 2001), we tested for publication bias with a rankcorrelation test between the individual effect sizes and the corresponding standard errors of each comparison (Viechtbauer 2010). We visualized the degree of publication bias with funnel plots.

\section{Results}

We identified 35 case studies that provided 83 comparisons between disturbed and undisturbed forests (42 comparisons between continuous and fragmented forest, 41 comparisons between undisturbed forests and hunted, selectively logged, or hunted and selectively logged forests). There were 25 comparisons of visitation rates, 44 of seed removal, and 14 of seed-dispersal distance (Supporting Information). From 1996 to 2009, studies of 51 tree species (Supporting Information) were conducted, almost all of them situated in tropical or subtropical forests (Fig. 1). Comparisons were not randomly distributed across the tropics; rather, they reflect geographical locations of research foci in tropical forests. More studies were conducted in the Neotropics than in Africa and Asia (Fig. 1).

\section{Effects of Human Disturbance}

Human disturbance (i.e., forest fragmentation, hunting, and selective logging) affected the 3 seed-dispersal components (visitation rate, seed removal, and seed-dispersal distance) differently (LRT $=7.2, p=0.028)$. Human disturbance tended to reduce visitation rates (Fig. 2), but this effect was not significant $(z=-1.3, p=0.20)$. In contrast, human disturbance significantly decreased seed removal ( $z=-3.7, p<0.001$, Fig. 2). Human disturbance tended to decrease seed-dispersal distances (Fig. 2); however, this effect was not significant $(z=-1.8, p=0.08)$.

Visitation rates and seed-dispersal distances were lower in fragmented and hunted or logged forests than in continuous and undisturbed forests; however, none of these effects were individually significant nor did the effect on these dispersal components differ significantly as a function of disturbance type (visitation rate: $Q<0.01, p=$ 0.94, seed-dispersal distance: $Q=0.01, p=0.92$ ) (Fig. 3). In contrast, fragmentation and hunting or selective logging differed significantly in their effects on seed removal $(Q=8.6, p=0.003$ ) (Fig. 3). Seed removal did not differ significantly between fragmented and unfragmented

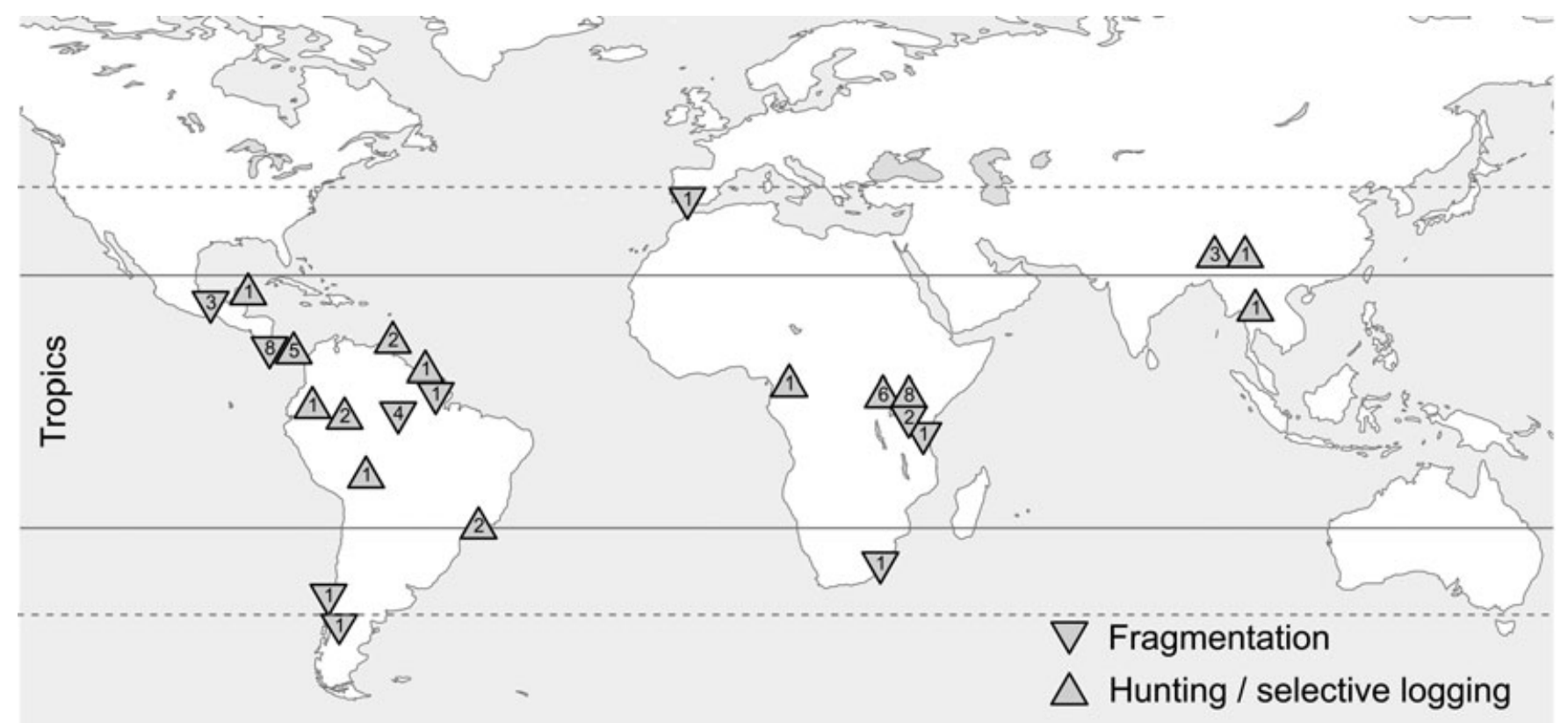

Figure 1. Location of studies included in the meta-analysis of the effects of forest fragmentation and hunting or selective logging on animal-mediated seed dispersal (numbers in symbols, number of comparisons between disturbed and undisturbed forest from each location [i.e., the number of plant species studied at each location]; dashed lines, subtropics, between $40^{\circ} \mathrm{N}$ and S; solid lines, tropics, between $23.5^{\circ} \mathrm{N}$ and S). 


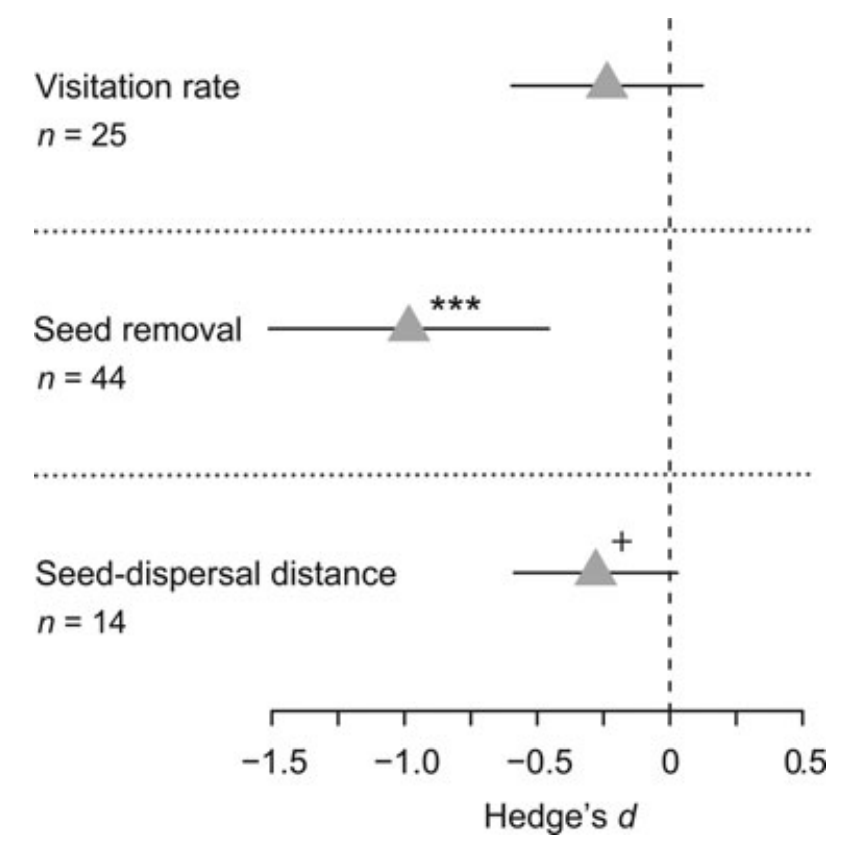

Figure 2. Effects of human disturbance (forest fragmentation, hunting, and selective logging) on different components of seed dispersal by animals. Weighted-mean effect size (Hedge's d) and 95\% CI for visitation rate, seed removal, and seed-dispersal distance are given $\left({ }^{+}, \mathrm{p}<0.1 ;{ }^{* * *}, \mathrm{p}<0.001\right)$.

forests ( $z=-1.2, p=0.25$ ), but was significantly lower in hunted or logged forests than in unhunted or unlogged forests $(z=-4.7, p<0.001)$ (Fig. 3).

We tested whether the lack of an effect of forest fragmentation on all components of seed dispersal was related to different sizes of forest fragments or continuous forests. Both the sizes of the forest fragments and continuous forests were unrelated to the respective effect sizes (fragment size: $z=0.4, p=0.69$, continuous forest size: $z=-0.3, p=0.80 ; n=42$ comparisons in both cases).

\section{Effects on Plants with Different-Sized Seeds}

In response to any type of human disturbance, visitation rates of frugivores were lower for large-seeded than for small-seeded tree species $(Q=4.2, p=0.040)$ (Fig. 4). Visitation rates to small-seeded tree species did not differ significantly between disturbed and undisturbed forests $(\tau=0.3, p=0.77)$, whereas visitation rates to largeseeded trees were significantly lower in disturbed than in undisturbed forests $(z=-2.4, p=0.015)$ (Fig. 4).

For seed removal, we tested separately whether fragmentation and hunting or selective logging affected plants with different-sized seeds because effect sizes for seed removal differed between the 2 types of human disturbance. The effect of forest fragmentation on seed removal did not differ between small- and large-seeded species $(Q=2.1, p=0.15)$ (Fig. 4$)$. In contrast, the ef-

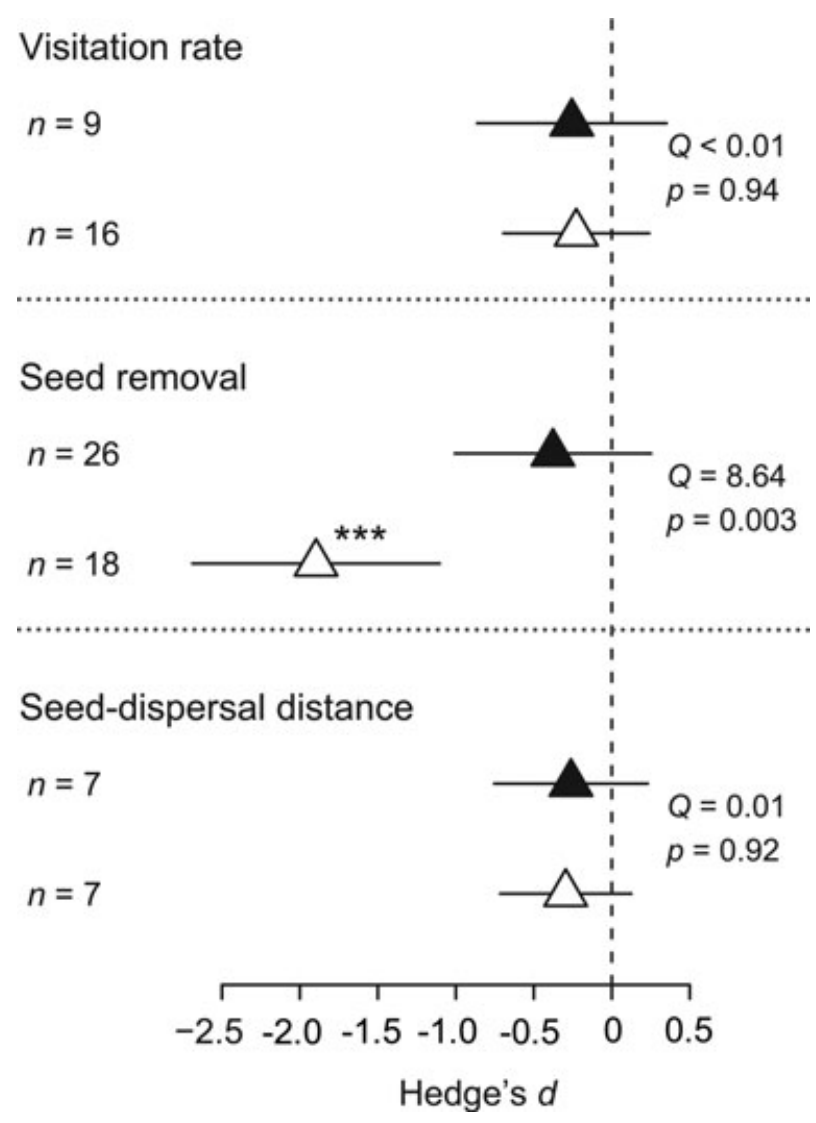

Figure 3. Effects of forest fragmentation and hunting or selective logging on each seed-dispersal component. Weighted-mean effect size (Hedge's d) and 95\% CI for visitation rate, seed removal, and seed-dispersal distance are given (filled symbols, effects of forest fragmentation; open symbols, effects of hunting and selective logging; $\mathrm{Q}$, differences in effect sizes between the 2 disturbance types; 3 asterisks, mean effect size that differs significantly from zero $[\mathrm{p}<0.001])$.

fects of hunting and selective logging on seed removal differed between small- and large-seeded species $(Q=$ 5.1, $p=0.024$ ) (Fig. 4). In hunted or logged forests, seed removal was lower than in undisturbed forests, but only for large-seeded plant species ( $z=-4.7, p<0.001)$ (Fig. 4). Effects of human disturbance in relation to seed size could not be evaluated for seed-dispersal distance because dispersal distances were only available for 2 smallseeded species.

\section{Autocorrelation and Publication Bias}

Spatial autocorrelation was absent from the residuals of all models (Supporting Information). Accordingly, effect sizes also did not differ among continents $(\mathrm{LRT}=1.71$, $p=0.43$ ). Phylogenetic autocorrelation was absent from the residuals of all models (Supporting Information). Effect sizes covered a wide range from negative through 


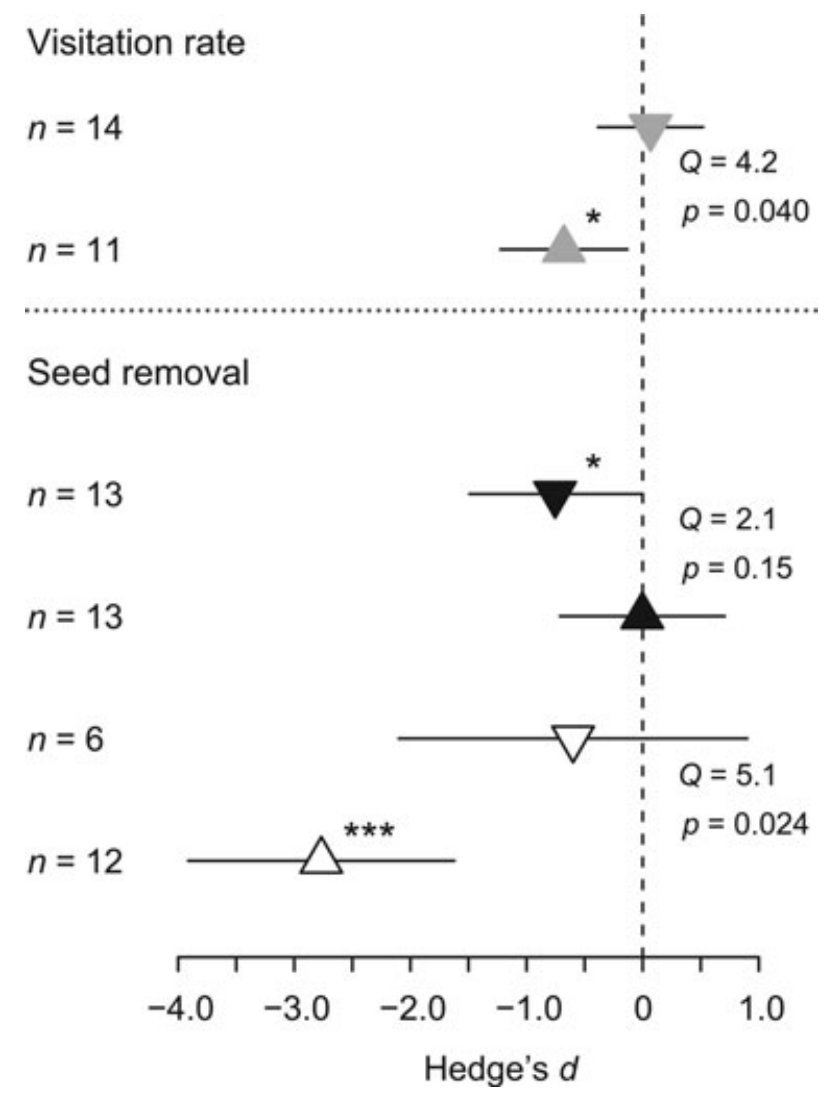

Figure 4. Effects of human disturbance on animal-mediated seed dispersal of small-and large-seeded tree species. Weighted-mean effect size (Hedge's d) and 95\% CI for visitation rate and seed-removal for small seeds $(<1 \mathrm{~cm}$, triangles point

down) and large seeds ( $\geq 1 \mathrm{~cm}$, triangles point up). For seed removal, effects were analyzed separately for studies of forest fragmentation (filled symbols) and bunting or selective logging (open symbols) (Q, differences in effect sizes between small- and large-seeded tree species; asterisks, mean effect sizes that differ significantly from zero $L^{*}, \mathrm{p}<0.05 ;{ }^{* * *}, \mathrm{p}<$ 0.001]).

neutral to positive effects, which suggests that both significant and nonsignificant findings had been published. Formally, analyses of visitation rates were not influenced by publication bias (rank correlation: $r=-0.15, p=$ 0.30) (Supporting Information). However, there was a significant negative correlation between effect size and standard error for seed removal (rank correlation: $r=$ $-0.34, p<0.001$ ) (Supporting Information). This potential publication bias was caused by 6 comparisons with large negative effect size and high standard errors. After excluding these comparisons, a publication bias was no longer evident (rank correlation: $r=-0.16, p=0.15$ ), and results were qualitatively identical. Analyses of dispersal distances appeared to be slightly affected by pub- lication bias (rank correlation: $r=-0.43, p=0.036$ ) (Supporting Information). This asymmetry was the result of a single data point (rank correlation excluding [Cramer et al. 2007a]: $r=-0.36, p=0.10$ ). Thus, our findings were not influenced by a biased sample of studies.

\section{Discussion}

\section{Effects of Human Disturbance}

Different components of the seed-dispersal process responded differently to forest fragmentation, hunting, and selective logging. The number of seeds removed, but not visitation rates, consistently decreased as forest disturbance increased, particularly in forests disturbed by hunting and logging activities. Investigating visitation rates of frugivores may therefore be insufficient for assessing human-induced effects on animal-mediated seed dispersal because visitation rates alone do not account for the number of fruits eaten or seeds removed. Large frugivores swallow more fruits and seeds per visit than small frugivores (Holbrook \& Loiselle 2009) and are often the first to be extirpated from disturbed forests (Peres \& Palacios 2007).

We found that seed-dispersal distances were slightly, but not significantly lower in forests disturbed by fragmentation or hunting and selective logging. This negative effect of human disturbance on dispersal distance was weaker than we had expected, probably because only 14 comparisons of seed-dispersal distances between disturbed and undisturbed forests were available for our meta-analysis. Moreover, most of these comparisons included seed-dispersal distances only up to a maximum distance (mostly up to $30 \mathrm{~m}$ ) and did not report longdistance seed dispersal. It is likely that long-distance seed dispersal is lower at disturbed than at undisturbed sites because of the loss of large frugivores that are able to disperse seeds over long distances (Stoner et al. 2007a; Holbrook \& Loiselle 2009). We recommend studies that, for example, apply molecular (Hardesty et al. 2011) or radio-tracking (Lenz et al. 2011) techniques to investigate the effects of different types of human disturbance on animal-mediated long-distance seed dispersal.

Even though results of single-site studies show negative effects of forest fragmentation on seed dispersal (e.g., Cramer et al. 2007a; Valdivia \& Simonetti 2007), we found that different components related to seed-dispersal processes, including visitation rates, number of seeds removed, and seed-dispersal distances, were not consistently lower in plants growing in fragmented forests than in plants growing in continuous forests. This result was not affected by the sizes of forest fragments or continuous forests that were not associated with the observed effect sizes. Even in the smallest fragment in our study ( 1 ha, Jorge \& Howe 2009), there was no significant decrease 
in seed removal and seed-dispersal distance. Because our analyses considered a reasonable gradient of fragment sizes from very small (1 ha) to medium-sized fragments (117 ha), our findings strongly suggest that, independent of the size of a forest fragment, seed-dispersal processes by animals could in general be maintained in fragmented forests. This is consistent with the notion that seed dispersal is often unaffected by forest fragmentation (e.g., Graham et al. 2002; Guariguata et al. 2002) or may even increase in forest fragments (Farwig et al. 2006; Neuschulz et al. 2011). Such positive effects of human disturbance, however, appear to be plant-species specific (Menke et al. 2012), and the resilience of seed dispersal to forest fragmentation is likely driven by plant species that are dispersed by many generalist frugivore species. We did not investigate effects of the vegetation matrix surrounding the forest fragments, which is also important for the maintenance of ecosystem functionality in fragmented forests (Laurance et al. 2002).

In contrast to the weak effects of forest fragmentation, direct effects of human activity had consistently negative effects on effect sizes of seed removal. Direct human disturbance may reduce the abundance of frugivores either by hunting (Peres 2000), by modifying forest structure due to increased logging intensities (Lambert 2011; Schleuning et al. 2011), or by both. Thus, whereas fragmentation affects the frugivore community and seed dispersal only indirectly, hunting and selective logging directly reduce frugivore abundance and modify the frugivore community (Wright 2003). Differences in consequences of direct (hunting or selective logging) and indirect (fragmentation) effects of human disturbance for ecosystem functioning in tropical forests have been also reported for other animal-mediated ecosystem processes such as insect pollination, leaf-litter decomposition, and predation by antbirds (Schleuning et al. 2011).

\section{Effects on Plants with Different-Sized Seeds}

Large-seeded trees received fewer visits by frugivores and had lower seed removal by frugivores than small-seeded trees in hunted or logged forests. This is consistent with the results of previous studies that show stronger negative effects of hunting or selective logging on largethan on small-seeded species (Babweteera \& Brown 2009; Menke et al. 2012). However, in contrast to single site studies (Cramer et al. 2007b; Moran et al. 2009), we found no significant difference in the response of smalland large-seeded plant species to forest fragmentation.

The greater sensitivity of large-seeded plant species to direct effects of human disturbance, and particularly to removal of animals by hunting, may result in an increase in abundance of small-seeded tree species and thus shifts in composition of tree species in hunted or logged forests (Stoner el al. 2007b; Vanthomme et al. 2010). Disruptions of animal-mediated seed dispersal could ultimately trigger a functional homogenization of the community of fruiting trees in tropical forests (Terborgh et al. 2008). Hunting could also reduce the abundance of large seed predators, such as agoutis (Dasyprocta spp.), but caching of seeds by rodents makes their ultimate effects on seed predation and seed dispersal difficult to predict (Wright et al. 2007). To investigate consequences of such secondary effects of hunting or other direct human disturbances, a meta-analysis on the influence of different types of human disturbance on seed predation and plant recruitment would be valuable.

\section{Concluding Remarks}

Our meta-analysis primarily applied to consequences of human disturbance for seed-dispersal interactions in tropical tree species. There are many more frugivore species in tropical forests than in other biomes (Kissling et al. 2009), and the proportion of animal-dispersed plant species is greater in tropical forests than in other biomes (Howe \& Smallwood 1982; Gentry 1988). Thus, our study focuses on the biome where plant-seed disperser interactions are most important. Nevertheless, animalmediated seed dispersal is also important for many temperate plant species, but few studies have investigated the consequences of human disturbance for temperate seed-dispersal interactions (Breitbach et al. 2010; Garcia et al. 2010).

We conclude from our results that hunting and selective logging negatively affect plant-seed disperser interactions and their outcomes, in particular the number of seeds removed. This finding suggests a consistent and generalized disruption of functional aspects of animal-mediated seed dispersal in tropical forests disturbed by ongoing human activities. The direct effects of hunting and selective logging on animal-mediated seed dispersal were stronger than the indirect effect of forest fragmentation. Our most important result was that large-seeded plant species were more susceptible to direct human effects than small-seeded plant species, likely because large frugivores are quickly extirpated from forests disturbed by hunting or logging activities. Thus, the disruption of plant-frugivore interactions can cause changes in composition of tree species in tropical forests; this finding underscores the central role of plant-animal interactions for maintaining species-rich tree communities.

\section{Acknowledgments}

J.S.M. is indebted to the "Stipendien-Stiftung RheinlandPfalz" for a scholarship and to J. R. Harris for language polishing. J.S.M., M.S. and K.B.-G. were supported by the research funding program Landes-Offensive zur Entwicklung Wissenschaftlich-ökonomischer Exzellenz (LOEWE) of Hesse's Ministry of Higher Education, Research, and 
the Arts. We thank all authors of the original studies who kindly contributed data to this meta-analysis and 2 anonymous referees and the associate and senior editors for their valuable suggestions.

\section{Supporting Information}

An overview of all studies included in the meta-analysis and a list of all tree species and their fruit and seed size, including full references for all original sources (Appendix S1); forest plots of effect sizes for each tree species and seed-dispersal component included in the meta-analysis (Appendix S2); tests for spatial and phylogenetic autocorrelation in the residuals of all final models (Appendix S3); and funnel plots to visualize potential publication bias for each seed-dispersal component (Appendix S4) are available online. The authors are solely responsible for the content and functionality of these materials. Queries (other than absence of the material) should be directed to the corresponding author.

\section{Literature Cited}

Aguilar, R., L. Ashworth, L. Galetto, and M. A. Aizen. 2006. Plant reproductive susceptibility to habitat fragmentation: review and synthesis through a meta-analysis. Ecology Letters 9:968-980.

Babweteera, F., and N. Brown. 2009. Can remnant frugivore species effectively disperse tree seeds in secondary tropical rain forests? Biodiversity and Conservation 18:1611-1627.

Bivand, R., M. Altman, L. Anselin, R. Assunção, and O. Berke. 2010. SPDEP: spatial dependence: weighting schemes, statistics and models. R package. R Foundation for Statistical Computing, Vienna. Available from http://cran.r-project.org/web/packages/spdep (accessed December 2011).

Breitbach, N., I. Laube, I. Steffan-Dewenter, and K. Böhning-Gaese. 2010. Bird diversity and seed dispersal along a human land-use gradient: high seed removal in structurally simple farmland. Oecologia 162:965-976.

Cordeiro, N. J., and H. F. Howe. 2003. Forest fragmentation severs mutualism between seed dispersers and an endemic African tree. Proceedings of the National Academy of Sciences of the United States of America 100:14052-14056.

Corlett, R. T. 2007. The impact of hunting on the mammalian fauna of tropical Asian forests. Biotropica 39:292-303.

Cramer, J. M., R. C. G. Mesquita, T. V. Bentos, B. Moser, and G. B. Williamson. 2007a. Forest fragmentation reduces seed dispersal of Duckeodendron cestroides, a central amazon endemic. Biotropica 39:709-718.

Cramer, J. M., R. C. G. Mesquita, and G. B. Williamson. 2007b. Forest fragmentation differentially affects seed dispersal of large and smallseeded tropical trees. Biological Conservation 137:415-423.

Farwig, N., K. Bohning-Gaese, and B. Bleher. 2006. Enhanced seed dispersal of Prunus africana in fragmented and disturbed forests? Oecologia 147:238-252.

Galetti, M., C. Donatti, A. Pires, P. Guimaraes, and P. Jordano. 2006. Seed survival and dispersal of an endemic Atlantic forest palm: the combined effects of defaunation and forest fragmentation. Botanical Journal of the Linnean Society 151:141-149.

Garcia, D., R. Zamora, and G. C. Amico. 2010. Birds as suppliers of seed dispersal in temperate ecosystems: conservation guidelines from real-world landscapes. Conservation Biology 24:1070-1079.
Gentry, A. H. 1988. Changes in plant community diversity and floristic composition on environmental and geographical gradients. Annals of the Missouri Botanical Garden 75:1-34.

Graham, C., J. E. Martinez-Leyva, and L. Cruz-Paredes. 2002. Use of fruiting trees by birds in continuous forest and riparian forest remnants in Los Tuxtlas, Veracruz, Mexico. Biotropica 34:589-597.

Guariguata, M. R., H. Arias-Le Claire, and G. Jones. 2002. Tree seed fate in a logged and fragmented forest landscape, northeastern Costa Rica. Biotropica 34:405-415.

Gurevitch, J., and L. V. Hedges. 2001. Meta-analysis. Combining results of independent experiments. Pages 347-369 in S. M. Scheiner and J. Gurevitch, editors. Design and analysis of ecological experiments. Oxford University Press, New York.

Hardesty, B. D., S. S. Metcalfe, and D. A. Westcott. 2011. Persistence and spread in a new landscape: dispersal ecology and genetics of Miconia invasions in Australia. Acta Oecologica 37:657-665.

Holbrook, K. M., and B. A. Loiselle. 2009. Dispersal in a Neotropical tree, Virola flexuosa (Myristicaceae): Does hunting of large vertebrates limit seed removal? Ecology 90:1449-1455.

Howe, H. F., and J. Smallwood. 1982. Ecology of seed dispersal. Annual Review of Ecology and Systematics 13:201-228.

Jordano, P., P.-M. Forget, J. E. Lambert, K. Böhning-Gaese, A. Traveset, and S. J. Wright. 2011. Frugivores and seed dispersal: mechanisms and consequences for biodiversity of a key ecological interaction. Biology Letters 7:321-323.

Jorge, M., and H. F. Howe. 2009. Can forest fragmentation disrupt a conditional mutualism? A case from central Amazon. Oecologia 161:709-718.

Kirika, J. M., N. Farwig, and K. Böhning-Gaese. 2008. Effects of local disturbance of tropical forests on frugivores and seed removal of a small-seeded Afrotropical tree. Conservation Biology 22:318328.

Kissling, W., K. Böhning-Gaese, and W. Jetz. 2009. The global distribution of frugivory in birds. Global Ecology and Biogeography 18:150-162.

Lambert, J. E. 1999. Seed handling in chimpanzees (Pan troglodytes) and redtail monkeys (Cercopithecus ascanius): implications for understanding hominoid and cercopithecine fruit-processing strategies and seed dispersal. American Journal of Physical Anthropology 109:365-386.

Lambert, J. E. 2011. Primate seed dispersers as umbrella species: a case study from Kibale National Park, Uganda, with implications for Afrotropical forest conservation. American Journal of Primatology 73:9-24.

Laurance, W. F., et al. 2002. Ecosystem decay of Amazonian forest fragments: a 22-year investigation. Conservation Biology 16:605-618.

Lenz, J., W. Fiedler, T. Caprano, W. Friedrichs, B. H. Gaese, M. Wikelski, and K. Böhning-Gaese. 2011. Seed dispersal distributions by trumpeter hornbills in fragmented landscapes. Proceedings of the Royal Society B 278:2257-2264.

Menke, S., K. Böhning-Gaese, and M. Schleuning. 2012. Plantfrugivore networks are less specialized and more robust at forestfarmland edges than in the interior of a tropical forest. Oikos DOI:10.1111/j.1600-0706.2011.20210.x

Morales, C. L., and A. Traveset. 2009. A meta-analysis of impacts of alien vs. native plants on pollinator visitation and reproductive success of co-flowering native plants. Ecology Letters 12:716-728.

Moran, C., C. P. Catterall, R. J. Green, and M. F. Olsen. 2004. Functional variation among frugivorous birds: implications for rainforest seed dispersal in a fragmented subtropical landscape. Oecologia 141:584-595.

Moran, C., C. P. Catterall, and J. Kanowski. 2009. Reduced dispersal of native plant species as a consequence of the reduced abundance of frugivore species in fragmented rainforest. Biological Conservation 142:541-552.

Morris, R. J. 2010. Anthropogenic impacts on tropical forest biodiversity: a network structure and ecosystem functioning perspective. 
Philosophical Transactions of the Royal Society B: Biological Sciences 365:3709-3718.

Myers, J. A., and K. E. Harms. 2009. Seed arrival, ecological filters, and plant species richness: a meta-analysis. Ecology Letters 12:1250-1260.

Neuschulz, E. L., A. Botzat, and N. Farwig. 2011. Effects of forest modification on bird community composition and seed removal in a heterogeneous landscape in South Africa. Oikos 120:1371-1379.

Paradis, E., J. Claude, and K. Strimmer. 2004. APE: analyses of phylogenetics and evolution in R language. Bioinformatics 20:289-290.

Peres, C. A. 2000. Effects of subsistence hunting on vertebrate community structure in Amazonian forests. Conservation Biology 14:240-253.

Peres, C. A., and E. Palacios. 2007. Basin-wide effects of game harvest on vertebrate population densities in Amazonian forests: implications for animal-mediated seed dispersal. Biotropica 39:304-315.

R Development Core Team. 2010. R: a language and environment for statistical computing. R Foundation for Statistical Computing, Vienna. Available from http://www.R-project.org (accessed December 2011).

Schleuning, M., et al. 2011. Forest fragmentation and selective logging have inconsistent effects on multiple animal-mediated ecosystem processes in a tropical forest. Public Library of Science ONE 6 DOI:10.1371/journal.pone.0027785

Schupp, E. W., P. Jordano, and J. M. Gómez. 2010. Seed dispersal effectiveness revisited: a conceptual review. New Phytologist 188:333-353.

Stoner, K. E., P. Riba-Hernandez, K. Vulinec, and J. E. Lambert. $2007 a$. The role of mammals in creating and modifying seed shadows in tropical forests and some possible consequences of their elimination. Biotropica 39:316-327.

Stoner, K. E., K. Vulinec, S. J. Wright, and C. A. Peres. 2007b. Hunting and plant community dynamics in tropical forests: a synthesis and future directions. Biotropica 39:385-392.

Terborgh, J., G. Nunez-Iturri, N. C. A. Pitman, F. H. C. Valverde, P. Alvarez, V. Swamy, E. G. Pringle, and C. E. T. Paine. 2008. Tree recruitment in an empty forest. Ecology 89:1757-1768.

Tummers, B. 2006. DataThief III. Available from http://datathief.org/ (accessed June 2012).

Valdivia, C. E., and J. A. Simonetti. 2007. Decreased frugivory and seed germination rate do not reduce seedling recruitment rates of Aristotelia chilensis in a fragmented forest. Biodiversity and Conservation 16:1593-1602.

Vanthomme, H., B. Bellé, and P.-M. Forget. 2010. Bushmeat hunting alters recruitment of large-seeded plant species in central Africa. Biotropica 42:672-679.

Viechtbauer, W. 2010. Conducting meta-analyses in R with the metafor package. Version 1.4-0. Journal of Statistical Software 36:1-48.

Wright, S. J., H. Zeballos, I. Dominguez, M. M. Gallardo, M. C. Moreno, and R. Ibanez. 2000. Poachers alter mammal abundance, seed dispersal, and seed predation in a Neotropical forest. Conservation Biology 14:227-239.

Wright, S. J. 2003. The myriad consequences of hunting for vertebrates and plants in tropical forests. Perspectives in Plant Ecology Evolution and Systematics 6:73-86.

Wright, S. J., A. Hernandéz, and R. Condit. 2007. The bush meat harvest alters seedling banks by favoring lianas, large seeds and seeds dispersed by bats, birds and wind. Biotropica 39:363-371.

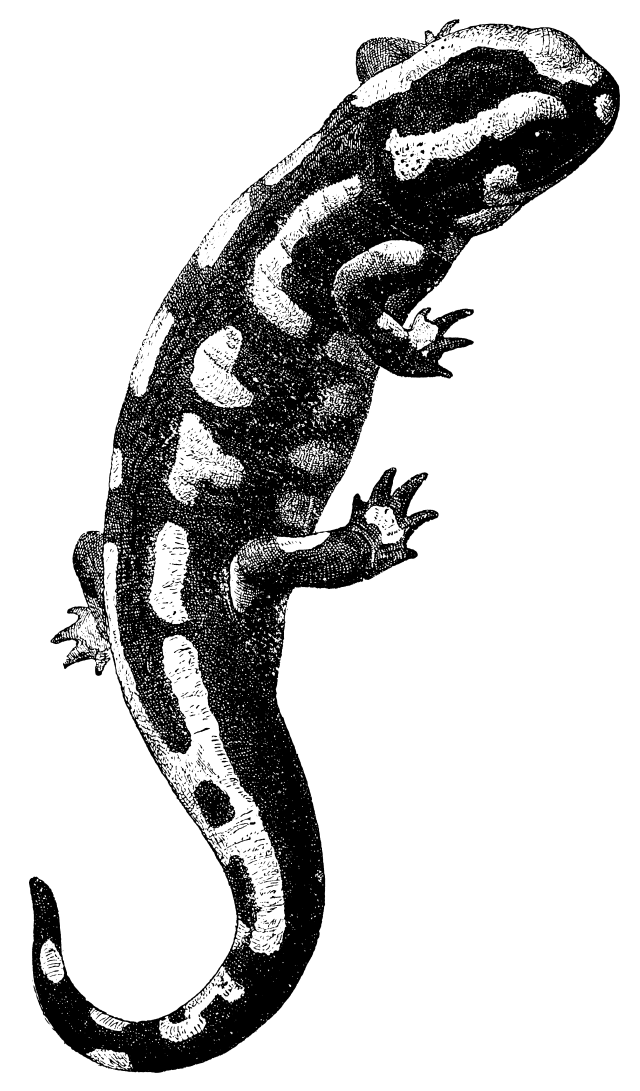

